\title{
Assisting Teaching Process and Management Based on the Informatization Platform
}

\author{
Weiyue Liu ${ }^{1}$, Jing $\mathbf{Y a}^{2}$ \\ ${ }^{1}$ School of Economics and Management, Tianjin Institute of Urban Construction, Tianjin, China \\ ${ }^{2}$ School of Materials Science and Engineering, Tianjin Institute of Urban Construction, Tianjin, China \\ Email: a12995@163.com,yajing@126.com
}

Received November 11, 2012; revised December 7, 2012; accepted December 14, 2012

\begin{abstract}
Based on the analysis of teaching environment, teaching process and course examination for the undergraduate, this paper discusses innovation of the teaching and learning reform of the curriculum for colleges and universities. In order to foster students' innovation and creativity as the guidance, the research aims at teaching students how to learn learning during the teaching process. In the paper, it is put forward that the application of modernization methods will optimize the teaching process, through designing and developing convenient and feasible information system for teaching process control. The system is able to play a role in assisting teaching process and its management, increasing the interactions between teaching and learning, paying attention to students' learning ability, creativity and imagination, so as to realize the purpose to optimize the teaching process and strengthen the teaching effectiveness.
\end{abstract}

Keywords: Teaching Process; Process Optimization; Creativity Fostering; Effectiveness Strengthening

\section{Introduction}

The information technology has revolutionary effects on the development of education and provides the possibility of constructing the database of network teaching resources. The direction of the teaching reform will focus on the innovation of the subject teaching by applying information technology. For innovative personnel training mode, the following three areas are very important: the combination between learning and thinking, the unification between knowing and action and to teach students in accordance with their aptitude. The areas must be paid high attention so as to stimulate the students' curiosity, cultivate the students' interest, and build the good atmosphere and environment in internal and external students' class in which students think things out for themselves and explore with more freedom. Some of domestic scholars mentioned the problem and discussed the possibility for using informatization method to solve it, as in [1-7]. However, there exists no example to realize teaching process control in China.

By the analysis of the undergraduate teaching environment, the teaching interaction and the course examination and setting cultivation of students' innovative creativity as the guidance, the authors put an idea that a teacher teaches students how to learn learning into the whole process of teaching and discusses a new method for the reform of curriculum teaching mode. To optimize the teaching process by applying the informatization platform, to utilize network-aided teaching measures to increase the interactions between teaching and learning, to pay attention to stimulating students' learning ability, creativity and imagination are the key points of the paper, in order to realize the purpose to optimize the teaching process and strengthen the teaching effectiveness.

\section{Observing and Thinking about the Teaching Environment}

In the past, universities and colleges in our country had been using a force-feeding teaching mode due to the limit of the school running conditions. Their teaching method has no essential difference with that of primary and secondary schools. The mode and its methods do not benefit to the inspiration of the students' innovation thinking and the foster of their innovation ability. The position and functions of colleges and universities in the personnel training are becoming more and more evident. Talent cultivation originates from the higher education. In order to adapt to the development requirements of the education globalization and the talent internationalization, our universities should innovate and change talent training mode. Our current plans relevant to the "engineering education", "outstanding engineers" and "quality engineering" sponsored by China Ministry of Education are very timely, and also necessary. Colleges and universities 
should devote major efforts to reforming the teaching mode, explore and implement the mechanism and the measures for teaching mode innovation adapt to economic and social development, and cultivate more senior specialized professionals suitable for the age developmental need.

The effectiveness of the teaching is influenced by the number of audients, and the more students there are, the poorer the effectiveness is. At present, the communication and understanding between teachers and students for our universities occur often only during a class for tens of minutes. Teachers' evaluation to the students' understanding knowledge and its degree only depends on a "standard" answer of examination paper. Such a "teaching" and "learning" activity is not conducive to stimulating students' interest in study, and not helpful to inspiring students' learning motivation. The teaching effect may be more easily as low as imagined. Evidently, students' mastering the knowledge relevant to the course and the teacher's evaluation to the studies of students are difficult to be accurately expressed by the results of the current assessment mode, and also can't be fully shown in the current teaching environment. Therefore, students deal irresponsibly with the exam. Because the exam results can not reflect the students' learning ability exactly, it happens necessarily that the student lacks of power to get high marks but a desire just to pass the exam changes common. It will result in students' lowering the interest in studying the course knowledge. In expanding international vision, enhancing the engineering practice ability, and building up learning-oriented organization, the teaching process is clearly unable to meet demand of the Times for personnel training $[8,9]$.

\section{Analysis on the Effect of Teaching Process}

The authors think that strengthening students' creativity and innovating talents training mode should start with a change for the process and method of undergraduate teaching. Current teaching process and teaching methods already can not adapt to the development of current education and the requirements of talent training. Teaching process and management must be assisted by utilizing informatization tool to change the current teaching method so as to make the interaction between teaching and learning. The most effective method to achieve one-to-more teaching is to build e-learning teaching environment. Informatization platform can optimize the teaching process in order to make the teaching process modernization, to make the teaching way more hommization and to make teaching evaluation more rationalization. Reference [10] pointed out that for the current undergraduate education, it existed that teachers guided students not enough. The effective solution is efficiently to use network aided teaching means. Several years ago, some colleges tried their attempt [11,12], but strengthening auxiliary teaching method by using informatization platform has not achieved significant results because of a limit in the campus cultural atmosphere and informatization popularity. At present stage, the conditions have changed. The information network facilities in the campus get well developed and the wireless education network goes into practical application phase. The network aided teaching becomes an urgent need.

The interactive teaching approach helps students think about, and is also the feedback process to check how much the student to learn the taught knowledge. Interactive teaching and learning method is effective and timely, and increases the interest with which the students study. If there is no interactive communication and if the teacher can't coach the students in time, the students will accumulate more and more problems and probably begin to disgust with learning. The inadequate investment of the teacher in teaching aggravates students' school-weary psychology. The fact shows that the teacher's teaching behavior affects highly on students' motivation and psychology on their learning. Only by continuous communication and in-time coaching, can the student maintain his or her interest in learning. The lack of teaching interaction and the shortage of college resources will become obstacles to innovate in teaching methods and to improve the learning efficiency.

\section{Defect of Course Examination and Its Root Cause}

The current examination way for undergraduate course is mainly based on an examination paper. The standard answer for the paper is mostly some of rote rules, from copy of the contents of the book. The exam is difficult comprehensively and accurately to reflect the student's ability in learning and innovation. High-mark result also loses its appeal to the students. This is why the students ignore the exam. If more than half of the students lose interest and expectation to high marks, it will affect a learning atmosphere for a class and even for whole college. This is a defect of the current way of examination.

The root cause resulting in the defect lies in the requirements of teaching program to the examination. The teaching program does not combine the teachers' teaching with the students' learning and not do the reality of the social development with teaching and learning process. The key of the teaching effect is not to check whether or not the teachers give all the contents of the textbooks, but to check how much the students have learned or how well.

Today in the informatization times, teaching method by completely copying textbooks, especially for those 
professional curriculums, will certainly give students fall-behind mode of thinking and out-of-date ideas. Teaching things by rote can neither improve the students' learning ability, nor cultivate students' creativity [13]. This phenomenon shows that the present education mode, even including undergraduate teaching ways, deserves reflection. In fact, for the teaching process under requirement of such an examination way, the teacher is difficult to teach and students are difficult to learn. The teacher did not have passion in teaching and the students have no interest in learning.

\section{Innovation and Practice for the Teaching Process}

On the way to investigate the course teaching for the undergraduate, the authors believe that it is important ways to enhance the interaction of class teaching and to increase the communication of the teacher with the students, improving the course teaching way and improving the teaching effect. In order to achieve such a goal, convenient informatization means must be widely utilized and the modern educational philosophy should be accepted. To make full use of network resources, to expand the communication between teachers and students, real-time to track the teaching process and to aid the teaching process and its management will help the teacher distribute his/her energy reasonably and help the students improve learning methods and increase their learning efficiency.

Using the network, this paper designs an auxiliary teaching information platform-teaching process control system. It is convenient for the teachers reasonably to arrange the communication with the students after class, course exercises and question and answer, so as to track the study condition for the students and realize network aided teaching management.

\subsection{System Structure}

The system is designed in a three-layer structure of Browser/Web/Data Base. In the Browser/Server system, a user can send a request to the Server by Browser. The server does processing to the request from the Browser and returns the information users want to the Browser. The $\mathrm{B} / \mathrm{S}$ structure simplified the client work and the client can work just by assembling Web browser. The server will take more work and database access and application program will be executed on the server. The browser sends only the request and the rest as data request, the processing, the results return and dynamic Web formation is finished by Web Server.

For the three-layer structure of Browser/Server, the representation layer, function layer and data layer are divided into three relatively independent units.
1) The first layer (the presentation layer): the Web browser. In the presentation layer, the display logic of the system is included and is located in the client. Its task is that a service request is proposed to the Web server on the network by the Web browser. After verifying user identity, Web server transfers the required home page to the client with the HTTP protocol and the client accepts the home page file transferred, showing it at the Web browser (the system using IE browser).

2) The second layer (function layer): the web server with the function to expand application program. In the function layer, transaction processing of the system connects with data. A request of data processing is put forward to database servers by the SQL, and then the database server submits results of data processing to the Web server. Such results are sent back to the client by the server.

3) The third layer (data layer): database server. In data layer there is data processing logic of system which is located in the database server. Its task is to accept database to the request of database manipulated by web server, to realize functions, such as querying, modifying, updating etc. for the database, and finally to submit the operation results to the web server. SQL server database is used by the system.

\subsection{System Feasibility}

The system of the teaching process control designed in the paper can be operated in Windows95/98 or other operating system and its development environment is Windows XP which can completely meet the requirement of system development. The system is developed by using ASP technology in combination with SQL Server database

Because the current popular $\mathrm{B} / \mathrm{S}$ structure is used by the system which is the browser/server mode, the client only needs to have browser which can login the Internet. The client can login the server to manage all kinds of information. And the server does not need to be equipped with too much configuration in which it can run ASP program such as Microsoft IIS. The whole system achieves the practical function at the least investment.

\subsection{System Function}

The teaching process control system includes the function modules, such as system announcement, class status, file download, online FAQ, management BBS and online exercises etc. The function modules cooperate with each other to realize the teaching process control, so as to enhance the teaching effect. System function modules are shown in Figure 1, in which there are 9 modules such as Home Page, Announcement, on-line FAQ etc.

Through the information system, the teacher can send 


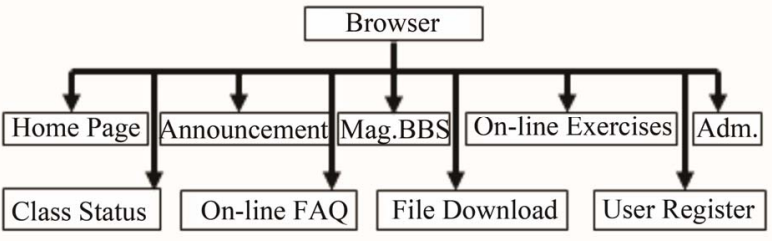

Figure 1. System function modules.

notices related to the course, record the student behavior at class (such as attendance, asking questions, answering questions, discuss each other and other situations, etc.), upload the reference material and exercises related to the course, deal with leaving message and make online FAQ through the QQ link. According to the information released at the system, students are able to understand the requirements of the teacher on the course and the class, in order to consolidate and review the key points of the course knowledge, download a useful file, do online exercises, view their learning situation (including their attendance, asking questions, answering questions and other status, etc), and at the same time, the students can also make the instant conversation (to one-to-one or more-to-one) with the teacher through QQ link. Figure 2 shows the home page of the system. Figure $\mathbf{3}$ is a section about information download, and by the section, the students can get the information related to the course.

From section "Class Status", the student's behavior at class will be found. The result is recorded in Figure 4. Some circumstances, such as being late, absence, asking questions and answering questions, etc. are truthfully reflected at the system. Based on the records, it is feasible to analyze the students' performance during studying the course. It can make the students understand their status at class and improve their performance so as to achieve better learning effectiveness.

Where in the Figure 4, P lv-personal leave; No A-no answer; a-good answer; c-answer but not right; Wcp-Sick leave.

At the above surface, there is no show for previous dialogues. The system cannot save the communication record among users. The problem can be solved through QQ system to which the system links.

Through QQ link (a dialogue platform at QQ website and frequently used in China), on-line FAQ may be realized. The teacher and students may make an on-line conversation. FAQ section is able to record and maintain the communication situation between the teacher and the students. Figure $\mathbf{5}$ is the interface for FAQ section and recording messages about conversation is shown in $\mathbf{F i}$ gure 6.

\subsection{System Application}

By using the teaching process control system designed in the paper, the teaching process shows a bright personalized feature and helps the students improve self-consciousness in their study.

While using the system, the students are required to login the browser by a username. By using this system for the first time, the registering users need to wait for teachers' (administrator) approval. Afterward, they may at any time login on the system. Through the system, they may understand the course schedule and participate in communication and interaction so as to consolidate

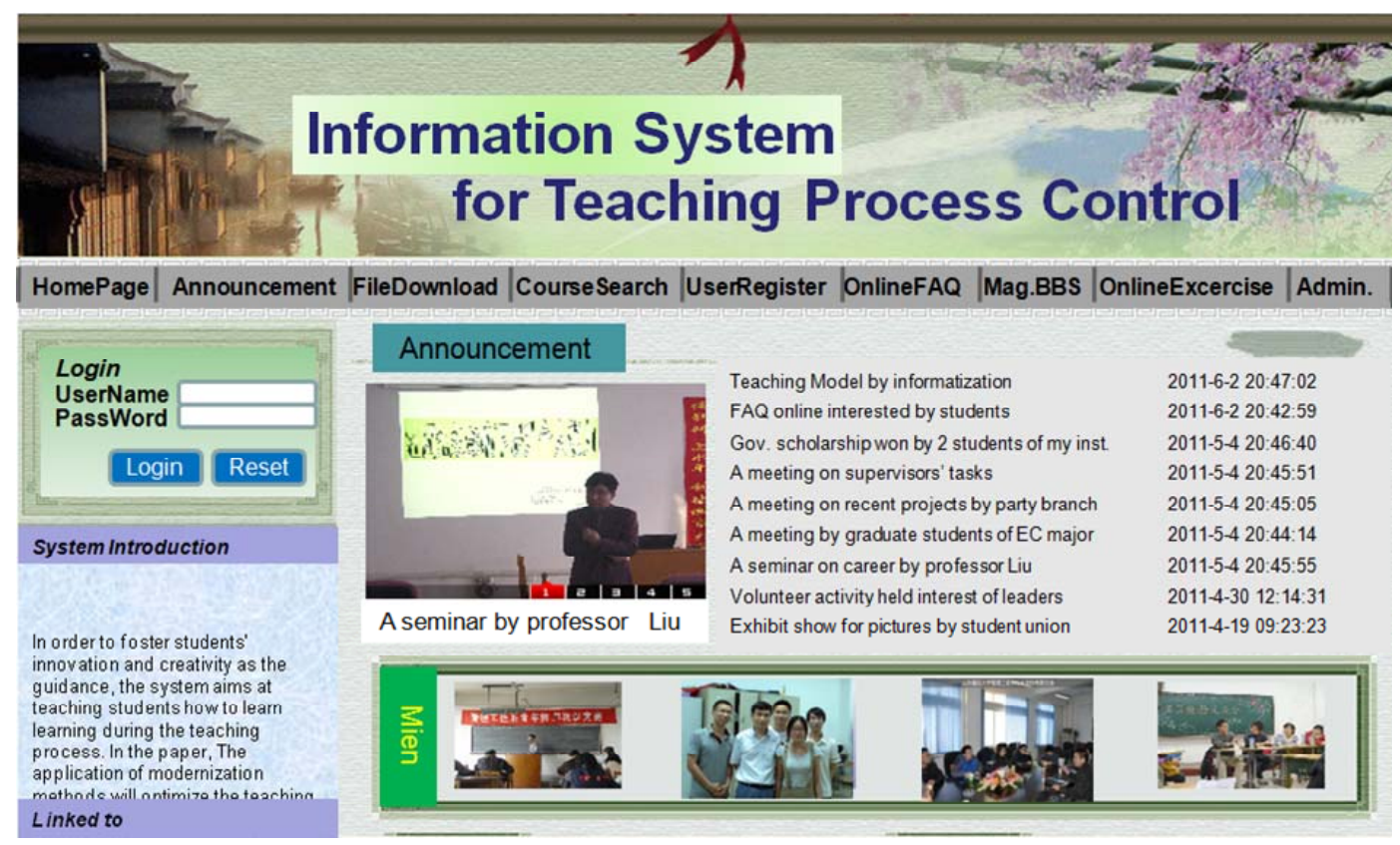

Figure 2. Home page to browse the system. 


\begin{tabular}{|c|c|c|c|c|}
\hline \multicolumn{5}{|c|}{ Files For Downloading } \\
\hline Series & Code & Coursewares & Owners & Upload Time \\
\hline 1 & 10071401 & College Computer Basis & Wang Debiao & $2010 / 2 / 10$ \\
\hline 2 & 10052101 & Management Principle & Liu Weiyue & $2010 / 3 / 12$ \\
\hline 3 & 10052104 & Economics & Liu Weiyue & $2010 / 3 / 12$ \\
\hline 4 & 10052105 & Acounting & Lv Xiaoxia & $2010 / 2 / 9$ \\
\hline 5 & 10052106 & Applied Statistics & Wang Shitong & $2010 / 2 / 10$ \\
\hline 6 & 10052107 & Systematic Engineering & Tang Zhijuan & $2010 / 3 / 10$ \\
\hline 7 & 10052108 & Technological Economics & Huo Xinhua & $2011 / 3 / 9$ \\
\hline 8 & 10052109 & Management Information System & Wang Zhongqin & $2012 / 4 / 10$ \\
\hline 9 & 1005382 & Customer Relationship Management & Xie Aiguo & $2012 / 4 / 15$ \\
\hline 10 & 10053803 & Enterprise Resource Plan & Li Fengfang & $2012 / 5 / 18$ \\
\hline 11 & 10053804 & IT Project Management & Wang Zhongqin & $2012 / 3 / 15$ \\
\hline 12 & 10053809 & Information Technology & Lai Dihui & 2012/6/19 \\
\hline
\end{tabular}

Figure 3. Information-download section.

\begin{tabular}{|c|c|c|c|c|c|c|c|c|c|c|c|c|c|c|c|c|c|c|c|}
\hline No. & Univ. CID & Students & 1 & 2 & 3 & 4 & 5 & 6 & 7 & 8 & 9 & 10 & 11 & 12 & 13 & 14 & 15 & 16 & 17 \\
\hline 1 & 10500101 & Zhang Chao & & & & & & & & & & $\mathrm{Plv}$ & & & & & & & P lv \\
\hline 2 & 10500102 & Hao Yu & NoA & c & c & & & NoA & & & & NoA & & c & c & & a & & c \\
\hline 3 & 10500103 & Tong Yanhao & & c & a & & a & $\mathrm{Plv}$ & a & & $\mathrm{a}$ & & & c & & $\mathrm{a}$ & c & & $\mathrm{Plv}$ \\
\hline 4 & 10500104 & Hu Dong & a & & a & $\mathrm{a}$ & & & & & $\mathrm{a}$ & & & & c & $\mathrm{a}$ & & $\mathrm{a}$ & $\mathrm{Plv}$ \\
\hline 5 & 10500105 & Fan Feilong & & & c & $\mathrm{a}$ & & & $\mathrm{NoA}$ & & & & & NoA & $\mathrm{a}$ & & a & & c \\
\hline 6 & 10500108 & Wang Zhuying & NoA & $\mathrm{a}$ & $\mathrm{a}$ & $\mathrm{a}$ & & & & c & & NoA & & c & & $\mathrm{c}$ & & c & c \\
\hline 7 & 10500109 & Ran Bo & & & a & & $\mathrm{P}$ lv & NoA & & & & & & NoA & $\mathrm{a}$ & & & $\mathrm{c}$ & c \\
\hline 8 & 10522110 & Bai Yali & NoA & a & & & & & a & & c & & & NoA & c & $\mathrm{a}$ & $\mathrm{NoA}$ & & c \\
\hline 9 & 10500111 & Lao Youhai & & NoA & NoA & & a & c & & a & & NoA & & & c & & & $\mathrm{a}$ & c \\
\hline 10 & 10500112 & Bao Wei & a & & $\mathrm{a}$ & $\mathrm{a}$ & & & & c & $\mathrm{a}$ & & & & & $\mathrm{a}$ & c & & $\mathrm{Plv}$ \\
\hline 11 & 10500113 & Ouyang Fuhai & & & a & & & & $\mathrm{NoA}$ & & & & & & NoA & & & c & P lv \\
\hline 12 & 10500114 & Yu Haibin & c & $\mathrm{a}$ & a & & & $\mathrm{a}$ & & NoA & c & & & c & & & W-cp & & $\mathrm{Plv}$ \\
\hline 13 & 10500115 & Xu Junfeng & c & & & a & NoA & c & & & c & c & & & & $\mathrm{a}$ & & c & c \\
\hline 14 & 10500116 & Liu Jian & & & c & & & $\mathrm{a}$ & NoA & & & & & NoA & & & NoA & & P lv \\
\hline
\end{tabular}

Figure 4. Student behavior at class.

what they learned.

1) Aiding learning

Through the 'File download' module, the students can in time understand the course requirements, "key knowledge points and the content of the class that they were unable to attend lectures. Through the "Management BBS" module, the students can view the message and the questions to which the teacher gave his/her answer.
Through the "online exercises" module, the students can do exercises, check the right and the wrong through submitting the answer and understand what they learnt. These modules in time provides the students with the convenience to review the course knowledge and to inspect learning effect

2) Enhancing communication

Through the "online FAQ” module, the students can 


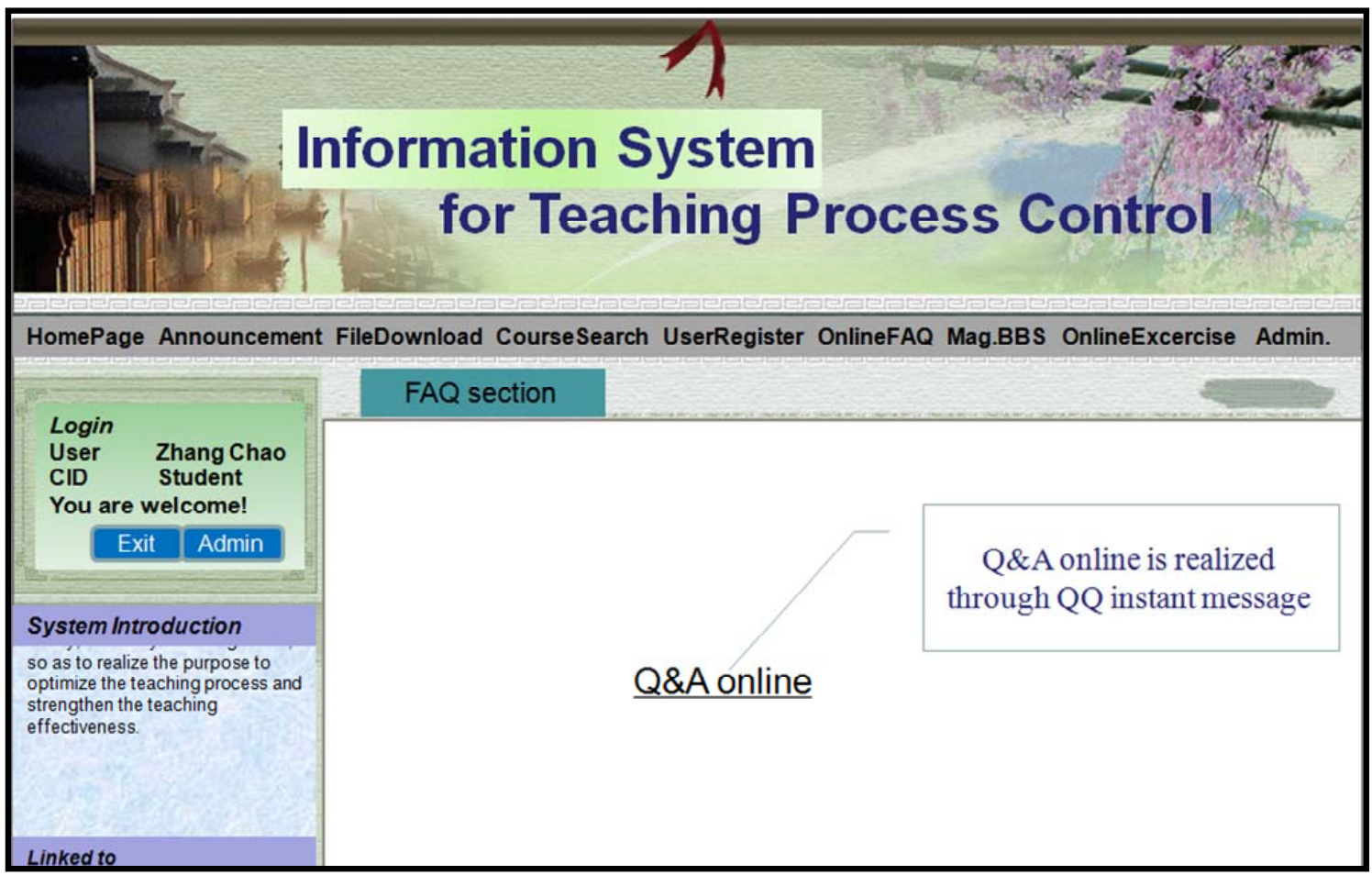

Figure 5. FAQ section.

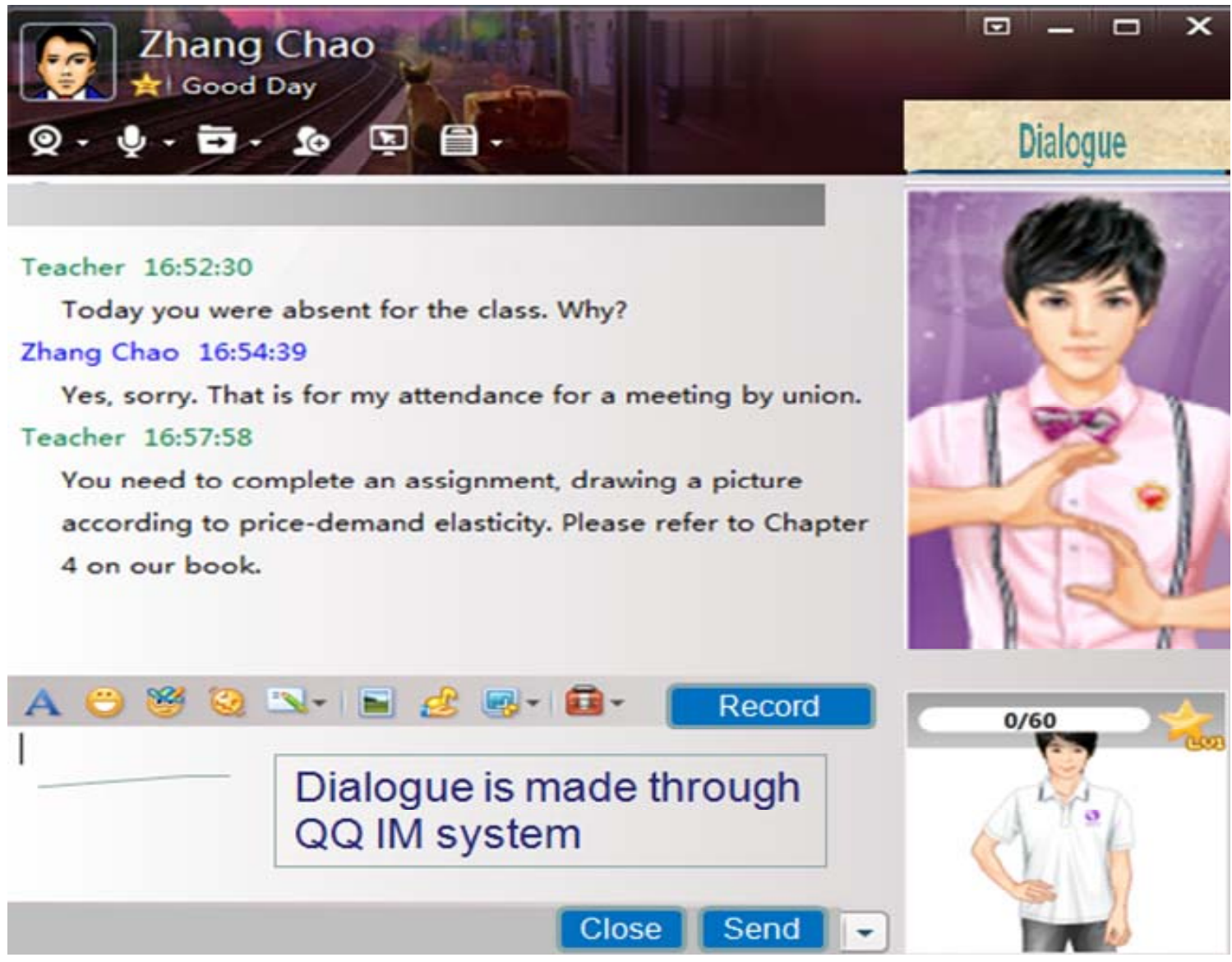

Figure 6. QQ record for conversation. 
online communicate with the teachers. Which the teacher is online, the system can hint to the students online. The system realizes online conversation between the teacher and the students through connection of the QQ platform. The students can seize the opportunity to communicate with the teacher. At usual occasion in the class, few of students can communicate directly with the teacher because of the limit of the conditions. In this system environment, such opportunities are equal, and any student can ask questions to the teacher, or answer the teacher's question.

3) Developing a habit

Students' behavior at class and during course learning stage can be written down in the system, or their online activities at the network are real-time recorded. Based on the record, the teacher can analyze the students' learning habits, and coach students to correct those habits not conducive to improve the studying effect, in order to make them get better learning results.

The system can not only aid teaching process, but also assist teaching management, so as to ease the teacher of the teaching pressure and solve the problem of communication between teachers and students.

With the popularization of the informatization means, the traditional teaching methods and assessment methods will be challenged. In the near future, profound changes in students' learning way will happen by the influence of the information technology. Written examination is no longer the unique way to assess students' learning results. Auxiliary teaching process and management by informatization will become the powerful weapon to make the challenge.

\section{Conclusion}

This article analyzes the students' behavior in the process of the course learning from the teaching environment, teaching interaction and course examination and discusses the role of the teaching interaction in improving students' learning ability. Combined with current situation and problems in the undergraduate teaching, the teaching process control system is designed and developed. The system can improve undergraduate teaching process and enhance the teaching effect.

\section{Acknowledgements}

Ma Fei and Zhou Yungu, students under my supervision, attended and completed a part of work related to this paper. Zhao Wei and Zong Cheng, our colleagues both from Tianjin Institute of Urban Construction, gave their feedbacks on testing and evaluating the teaching process control system designed in the paper. The authors would like to thank them for their sincere support and help.

\section{REFERENCES}

[1] M. Fu, "Reasonable Utilization of Modern Teaching Measure and Traditional Teaching Measure,” Xi'an Society Science, Vol. 24, No. 6, 2011, pp. 121-123.

[2] L. F. Liu, "Discussion on Task-Driving Teaching under Network Environment,” China Science \& Technology Overview, Vol. 11, No. 14, 2012, pp. 195-195.

[3] X. H. Ni, S. Q. Zhang and Y. C. Ma, "Foster Innovation Ability by Utilizing Information Teaching Tool," China Educational Technique \& Equipment, Vol. 26, No. 15, 2012, pp. 125-127.

[4] W. Y. Hu, "Research and Realization of Leading Teaching,” Academic Research, No. 4, 2012, pp. 15-16.

[5] Y. X. Yang and F. L. Zhou, "Design and Realization of Teaching Information Management System Based on Internet," Pioneering With Science \& Technology Monthly, Vol. 24, No. 4, 2010, pp. 138-139.

[6] Q. L. Liu, “Constructing Teaching Information Management Platform to Improve Students' Information Literacy,” Science Message, Vol. 24, No. 14, 2007, p. 37.

[7] H. Peng, J. Huang and Z. H. Chen, "Research on College Teaching Information," Journal of Hubei University of Technology, Vol. 21, No. 2, 2006, pp. 79-82.

[8] T. Qu, J. Y. Lu and X. J. Chen, "Research on Electronic Educational Administration Platform Based on Web Service,” Taiyuan Science and Technology, Vol. 29, No. 10, 2008, pp. 15-16.

[9] J. L. Sun, "Discussion on the Network-Aided Teaching," China Educational Technique \& Equipment, Vol. 26, No. 6, 2012, pp. 137-138.

[10] B. Zhou, "Peking University Education and Research Internet: Education Informatization 'Seaman',' China Education Network, Vol. 7, No. 8, 2010, pp. 64-65.

[11] Y. Luo, Y. Zhang, Q. Shen and Y. C. Zhao, "Based on the Information Management Mode to Improve Evaluation Effectiveness for the Applied Undergraduate Teaching," China Education Information, Vol. 16, No. 7, 2010, pp. 6-8.

[12] H. H. Li, "Characteristics and Enlightenment to Promote the Development of the Reform of University Teaching by E-Learning of the Chinese University of Hong Kong," Higher Education Exploration, Vol. 23, No. 9, 2010, pp. 30-36.

[13] D. K. Ge, "E-Leaming Data Mining: Mode and Application,” China Higher Education Research, Vol. 21, No. 3, 2012, pp. 8-14. 